\title{
COSIGN - developing an optical software controlled data plane for future large-scale datacenter networks
}

Galili, Michael; Kamchevska, Valerija; Fagertun, Anna Manolova; Ruepp, Sarah Renée; Berger, Michael Stübert; Oxenløwe, Leif Katsuo; Dittmann, Lars

\section{Published in:}

Proceedings of 17th International Conference on Transparent Optical Networks

Link to article, DOI:

10.1109/icton.2015.7193375

Publication date:

2015

Document Version

Publisher's PDF, also known as Version of record

Link back to DTU Orbit

Citation (APA):

Galili, M., Kamchevska, V., Fagertun, A. M., Ruepp, S. R., Berger, M. S., Oxenløwe, L. K., \& Dittmann, L. (2015). COSIGN - developing an optical software controlled data plane for future large-scale datacenter networks. In Proceedings of 17th International Conference on Transparent Optical Networks [7193375] IEEE. https://doi.org/10.1109/icton.2015.7193375

\section{General rights}

Copyright and moral rights for the publications made accessible in the public portal are retained by the authors and/or other copyright owners and it is a condition of accessing publications that users recognise and abide by the legal requirements associated with these rights.

- Users may download and print one copy of any publication from the public portal for the purpose of private study or research.

- You may not further distribute the material or use it for any profit-making activity or commercial gain

- You may freely distribute the URL identifying the publication in the public portal 


\title{
COSIGN - Developing an Optical Software Controlled Data Plane for Future Large-Scale Datacenter Networks
}

\author{
Michael Galili, Valerija Kamchevska, Anna M. Fagertun, Sarah Ruepp, Michael S. Berger, \\ Leif K. Oxenløwe, and Lars Dittmann \\ DTU Fotonik, Technical University of Denmark, Ørsteds Plads, 2800 Kgs. Lyngby, Denmark \\ Tel: (+45) 4525 3779,e-mail:mgal@fotonik.dtu.dk
}

\begin{abstract}
This talk will present the work of the EU project COSIGN targeting the development of optical data plane solutions for future high-capacity datacenter networks (DCNs). Optical data planes with high capacity and high flexibility through software control are developed in order to enable a coherent management and orchestration of all resources in the datacenter including the datacenter network.
\end{abstract}

\section{BACKGROUND}

Datacenters are experiencing dramatic growth in size and numbers. This has been the case for several years and there are no signs to indicate any immediate change. The vast success of cloud networking and datacenter applications as well as the rapidly growing data volumes has resulted in increased requirements for efficient and DCN infrastructure.

At present, due to cost and market availability, data center infrastructures are usually built with commodity Ethernet packet switches. Several different DCN architectures exist [1], but the fat-tree topology [2] is the most popular. The fat-tree topology is generally challenged when scaling to very large DCNs where the complexity and cost does not scale favorably. The key limitation of traditional fat-tree architectures is that scaling results in a many-tiered network due to the limited number of ports per switch.

Currently, the different resources of a data centre are managed using different and often incompatible control and management tools. Consequently, it is very challenging to create a common view of all available resources and plan and deploy new services accordingly. Implementing new services or optimising existing ones is also challenging due to the lack of a common control and management interface and the numerous manual steps are prone to cause errors.

Future-proof DCN architectures that support scaling far beyond current capacity while ensuring low power dissipation, low cost and low latency need to be developed. Fundamentally new data plane technologies are required, as well as a new framework for control and service orchestration.

\section{COSIGN}

The COSIGN (Combining Optics and SDN In next Generation data centre Networks) [3] project proposes new DCN architectures based on novel optical technologies as well as an SDN based network-control and service orchestration platform. The target is to enable dynamic, on-demand, low-latency and ultra-high bandwidth data centre operation.

The efforts in achieving this will be on several fronts.

Novel optical components will be introduced to improve data-plane performance and scalability. High radix, low power Ethernet switches will be introduced. Several optical switch technologies will be applied to achieve transparent optical connections. Spatial optical multiplexing in e.g. multi-core fibres will be applied to increase the information density multiplying the data capacity. Hollow core fibres will be used to reduce transmission latency to the absolute minimum.

Novel DCN architectures will be developed to improve scalability and capacity. A hybrid architecture comprising a conventional network of Ethernet switches as well as optical circuit switching is investigated as a conservative introduction of advanced optical technology in the DCN. More disruptive DCN architectures are investigated including a multi-domain architecture comprising time domain multiplexing (TDM) and wavelength division multiplexing (WDM) for communication in- and between DCN domains. Finally, a ring-based topology with hierarchical optical network nodes is studied with the aim of radically reducing DCN complexity and improving scalability.

SDN-based control will have visibility of the capabilities of optical devices and expose them in a flexible multilayer network service infrastructure. Exposing relevant northbound abstractions over the SDN layer will enable provisioning of both connectivity and network services as part of the overall data centre resource orchestration.

\section{REFERENCES}

[1] A. Hammadi et al.: A survey on architectures and energy efficiency in data center networks, Computer Communications, vol. 40, pp. 1-21, 2014.

[2] M. Al-Fares et al.: A scalable, commodity data center network architecture, in Proc. SIGCOMM 2008.

[3] www.fp7-cosign.eu/ 